\title{
Strategies to Reduce Transient Liquid Phase Bonding Time for the Die Attach of Power Semiconductors
}

\author{
Sunghyun Sohn*, Daewon Kim**, Hongpyo Kim*** and Namhyun Kang****, $\dagger$ \\ *Naval Systems Research Team 2, Defense Agency for Technology and Quality, Jinju, 52851, Korea \\ **Technology Planning Management Team, Defense Agency for Technology and Quality, Jinju, Korea \\ ***C4ISR Systems Team 2, Defense Agency for Technology and Quality, Gumi, Korea \\ ****Department of Materials Science and Engineering, Pusan National University, Busan, 46241, Korea
}

†Corresponding author : nhkang@pusan.ac.kr

(Received March 31, 2020 ; Revised April 20, 2020 ; Accepted April 27, 2020)

\begin{abstract}
Wide band gap (WBG) power semiconductors have superior properties and accordingly demand for WBG semiconductors has grown recently in various fields, including national defense applications. Since WBG power semiconductors operate in high temperature conditions, interconnects with high temperature reliability are required. Transient liquid phase bonding (TLPB) is emerging as one of the die attach technologies for WBG power semiconductors. However, TLPB has drawbacks, such as long bonding times and void formation. We investigated various methods to address the shortcomings of TLPB, and determined TLPB time can be reduced and void formation can be suppressed through the development of process and interlayer design. This study describes the principles, strengths and weaknesses of each process and interlayer material design.
\end{abstract}

Key Words : Transient liquid phase bonding, Die attach, Power semiconductors, Wide band gap, Interlayer design

\section{Introduction}

Power semiconductors are used to control and convert electric energy in various fields such as electric power, automotives, home appliances, aerospace, geothermal power plants, weapons systems, etc. ${ }^{1,2)}$. However, with increasing demand for high power, efficiency, and switching frequency, Si-based power semiconductors are faced with their limitations ${ }^{3}$. For example, the U.S. Navy anticipates that an electromagnetic aircraft launch system would require to increase the peak power up to 200 MW for a few seconds and the navy would need high-power systems for propulsion, sonar, and auxiliary equipment for naval weapon systems ${ }^{4}$. The wide band gap (WBG) power semiconductor is a substitute for the power semiconductor used currently because of its many technical advantages such as high efficiency and miniaturization of electronic products as well as reduction of global warming gas emission ${ }^{5)}$. Fig. 1 shows the summary of characteristics for current and future WBG semiconductors. The WBG power semiconductor can be used at high voltage due to its wide band gap and stablibility at high temperature environment with its high thermal conductivity ${ }^{6,7)}$. Furthermore, high mobility and concentration of the charge carriers in WBG se- mi-

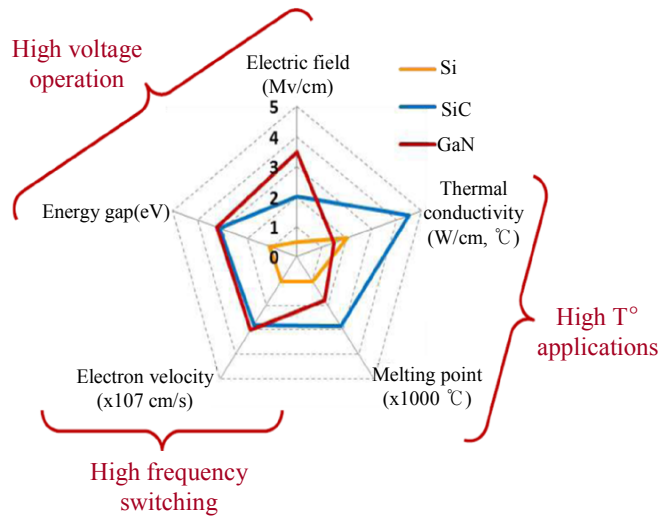

Fig. 1 Summary of characteristics for $\mathrm{Si}, \mathrm{SiC}$ and $\mathrm{GaN}^{6)}$ 
conductors allow high speed switching ${ }^{3,6)}$. Representative WBG power semiconductors are $\mathrm{SiC}$ and $\mathrm{GaN}$. The high temperature stability makes them operate approximately at $350{ }^{\circ} \mathrm{C}$. Additionally, they can reduce the size of modules because they do not require an additional cooling system $^{8)}$. The possibility of miniaturization increases the power density of the device, which increases the working temperature, so that the WBG power semiconductors are used in a high temperature environment ${ }^{5)}$.

Die attach is one of the important packaging steps in high-power electronics systems. The purpose of die attach is to provide structural base for electrical interconnections as well as to serve as a heat dissipation path $^{8)}$. In order to ensure the functionality and reliability of WBG power semiconductors, a die attach suitable for high temperature environment should be attained,10). The solders used for die attach and their melting point are shown in Fig. $2^{11)}$. Pb-rich solders usually have a melting point above $260{ }^{\circ} \mathrm{C}$ and can be used as a die-attach material for WBG power semiconductors. However, the use of $\mathrm{Pb}$ is prohibited because of the environmental hazard $^{12)}$. Therefore, solders containing $\mathrm{Pb}$ should be replaced for the die-attach material of WBG semiconductors. The Sn-based solders have a slightly lower melting temperature than the $\mathrm{Pb}$-rich solders. Considering that the advancing technology requires the high operation temperature, the WBG semiconductors require a solder having a melting point above $300{ }^{\circ} \mathrm{C}$. In particular, military products operate in harsher environments than commercial products, therefore requiring a die attach with a higher melting point than the normal Snbased solders $^{13)}$. As shown in Fig. 2, the solders including $\mathrm{Au}$ are the possible candidates. Due to the characteristics of the soldering process, a process temperature higher than the melting point of the solders is required to perform die attach. Therefore, the solders having a

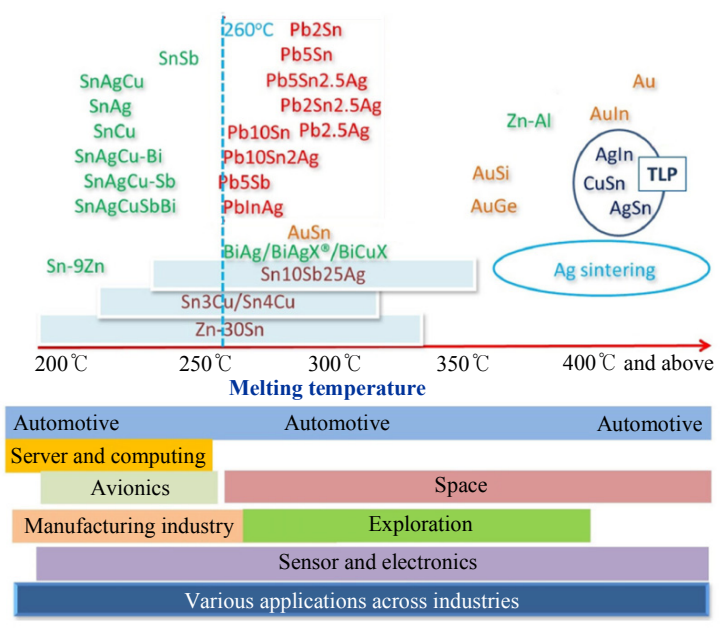

Fig. 2 Die-attach materials and the applications ${ }^{11)}$ melting point above $300{ }^{\circ} \mathrm{C}$ cause a damage to the WBG semiconductors during a die attach ${ }^{14)}$. That is why there is a continuous need to develop the interconnects composed with the elements of high melting temperature and the processes with a reduced-operation temperature as compared with the normal soldering. As a solution, the die attach for the WBG semiconductor replaces the conventional solders with Ag soldering or transient liquid phase bonding (TLPB) $)^{15,16)}$.

Ag sintering and TLPB produce interconnects with a higher re-melting temperature than the process temperature. Due to the characteristics, Ag sintering and TLPB are emerging with a die-attach technology of WBG power semiconductors. Ag sintering uses the paste consisting of $\mathrm{Ag}$ micro- or nanoparticles to form interconnects $^{17)}$. Paste contains organic additives so that the Ag particles do not interact with each other before the bonding process. Since the driving force of sintering becomes different with respect to the particle size, the process temperature and time are applied with various levels ${ }^{18)}$. Moreover, the bonding time needs to be optimized depending on the sintering process that is conducted with or without a pressure ${ }^{15)}$. Ag sintering has the advantage as follows: Ag has excellent electrical and thermal properties and the melting point of the joint after sintering is $961{ }^{\circ} \mathrm{C}$, which is the melting point of bulk Ag. Moreover, the normal operation temperature for $\mathrm{Ag}$ sintering is $200-300{ }^{\circ} \mathrm{C}$, which is much lower than the melting temperature of the sintered joint. However, there is the disadvantage that the reliability of the joint is reduced when residual organic additives exist in the joint ${ }^{19)}$. There are attempts to use $\mathrm{Cu}$ particles to reduce the cost of expensive Ag particles, but they still have the unavoidable problem of $\mathrm{Cu}$ oxidation $1^{9)}$.

TLPB is also conducted at low temperature and produces the melting point of the joint higher than the process temperature ${ }^{5)}$. TLPB is a process in which a metal with low melting point, called interlayer such as $\mathrm{Sn}$, is inserted between metals having high melting point, which is called metallization. And then, it proceeds at a temperature slightly higher than the melting point of the interlayer. Metallization is maintained at the process temperature so that the metallization dissolves into the liquid interlayer ${ }^{20)}$. Dissolved metallization forms an intermetallic compound (IMC) interacting with the interlayer. While the liquid interlayer is consumed, IMC is produced over time. When the TLPB is completed, it forms an IMC joint with a higher melting point than the process temperature. TLPB is more competitive than Ag sintering, due to its similarity to existing soldering processes and compatibility with the current facility in industry. Since metallization is dissolved and diffused into the joint, the mechanical, electrical and thermal 
properties of the joint are similar to metallization ${ }^{8)}$. However, TLPB has a disadvantage that it takes long time to complete the reaction since TLPB is a joining method requiring diffusion of metallization as described above $^{21)}$. For example, it takes approximately 90 minutes for the joint to be filled with IMC when TLPB is performed with pure Sn interlayer with a thickness of 25 $\mu \mathrm{m}$ and $\mathrm{Cu}$ metallization at $250{ }^{\circ} \mathrm{C}$. Bonding time delayed reduces the reliability of the device during the process and causes a thermal stress induced by difference in the coefficient of thermal expansion (CTE) of the components, which can affect performance ${ }^{14)}$. Therefore, reducing the bonding time of TLPB is the ultimate goal for this process. Kirkendall void formation due to the difference in diffusion rate and volume shrinkage generated in TLPB is also an issue to be solved ${ }^{22)}$.

This study will examine the research trends of reducing the TLPB time. It also investigates the methods to suppress defects such as kirkendall voids produced during the TLPB. Recently, the TLPB study is conducted for the process of TLPB and design of an interlayer. The objective of this study is to critically summarize and review the various aspects of process and interlayer design for the TLPB, and finally to suggest the future direction of TLPB development.

\section{Process development to reduce TLPB time}

\subsection{Application of temperature gradient during TLPB}

The conventional TLPB is performed in isothermal condition. New approach to reduce TLPB time was conducted with applying temperature gradient. Zhao et $a l^{23)}$ applied TLPB consisting of $\mathrm{Cu} / \mathrm{Sn} / \mathrm{Cu}$ structure under isothermal and temperature-gradient conditions. Fig. 3 shows the microstructural evolution of the $\mathrm{Cu} / \mathrm{Sn} /$ $\mathrm{Cu}$ solder joints after reflowed at $250{ }^{\circ} \mathrm{C}$ for various durations. The isothermal condition showed symmetric

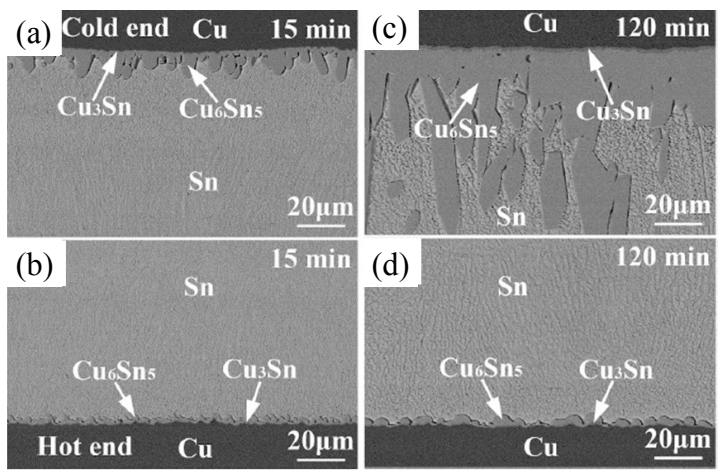

Fig. 3 Microstructural evolution of the $\mathrm{Cu} / \mathrm{Sn} / \mathrm{Cu}$ solder joints after reflowed at $250{ }^{\circ} \mathrm{C}$ for various durations: (a,c) cold end for 15 and $120 \mathrm{~min}$; (b,d) hot end for 15 and $120 \mathrm{~min}^{23)}$
IMC growth, while the temperature-gradient condition showed asymmetric IMC growth that was prominent at the cold end. This is because $\mathrm{Cu}$ dissolved in $\mathrm{Sn}$ under the temperature-gradient condition continuously migrated from the hot end to the cold one. In the hot end, the $\mathrm{Cu}$ is insufficiently supplied and dissolution of $\mathrm{Cu}$ occurs continuously. In the cold end, however, the IMC grew rapidly due to the addition of $\mathrm{Cu}$ flux by the temperature gradient. Therefore, the hot end produces only dissolution and the cold one produces only IMC growth. Isothermal condition caused dissolution and IMC growth at the both ends of $\mathrm{Cu}$ interface at the same time. Due to the elimination of wet grain boundary by IMC growth, the dissolution rate of $\mathrm{Cu}$ and the IMC growth decrease simultaneously. Thus, the IMC growth in the temperature gradient was faster than that in the isothermal condition. When TLPB was performed at $250{ }^{\circ} \mathrm{C}$ for 2 hours, the IMC thickness became to be $16 \mu \mathrm{m}$ in isothermal aging and the IMC thickness of $50 \mu \mathrm{m}$ in temperature-gradient condition. The authors also confirmed that the larger temperature gradient produced the more $\mathrm{Cu}$ flux and the faster IMC growth during TLPB ${ }^{24,25)}$. Kinetic analysis of the IMC growth during TLPB revealed that IMC grew by volume diffusion-controlled mechanism in isothermal TLPB and by reaction-controlled mechanism in temperature-gradient TLPB.

\subsection{Application of electric current during TLPB}

Feng et $a{ }^{26)}$ applied an electric current to the $\mathrm{Cu} / \mathrm{Sn} /$ $\mathrm{Cu}$ structure in a vacuum furnace and produced TLPB. With no current applied, the IMC grew preferentially at the interface between $\mathrm{Cu}$ and $\mathrm{Sn}$. However, the application of an electric current made the IMC grow faster as compared to the condition with no current applied. Fig. 4 shows the IMC morphology growing in $\mathrm{Cu}-\mathrm{Sn}$ intermetallic joints under a current density of $1.0 \times 10^{2}$ $\mathrm{A} / \mathrm{cm}^{2}$ at $260{ }^{\circ} \mathrm{C}$. Dissolution of $\mathrm{Cu}$ occurred and IMC was hardly formed at the cathode. However, $\mathrm{Cu}$ dissolution did not occur and only IMC grew at the anode. This is because the dissolved $\mathrm{Cu}$ moved from the cath-

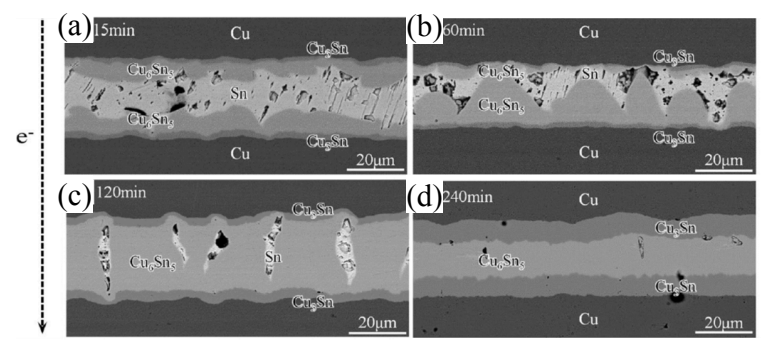

Fig. 4 Morphology evolution in $\mathrm{Cu}-\mathrm{Sn}$ intermetallic joints under a current density of $1.0 \times 10^{2} \mathrm{~A} / \mathrm{cm}^{2}$ at $260{ }^{\circ} \mathrm{C}$ for various times: (a) $15 \mathrm{~min}$, (b) 60 $\min ,(c) 120 \mathrm{~min},(\mathrm{~d}) 240 \min ^{26}$ 
ode to the anode by elctromigration, i.e., the $\mathrm{Cu}$ flux generated. As in the case of the temperature-gradient condition, IMC was not nearly formed and only $\mathrm{Cu}$ dissolved in the cathode. Therefore, it is possible to reduce the bonding time in which the dissolution rate attributing to the IMC growth remained nearly constant during the process. Furthermore, the IMC growth in the electric current was much faster than that in the temperature-gradient condition (Fig. 3).

They also studied the effect of the magnitude of the applied current on the growth rate of IMC. The growth rate of IMC was $0.107 \mu \mathrm{m} / \mathrm{min}$ when the applied current was $1.0 \times 10^{2} \mathrm{~A} / \mathrm{cm}^{2}$ at $260{ }^{\circ} \mathrm{C}^{26)}$. For the applied current of $2.0 \times 10^{2} \mathrm{~A} / \mathrm{cm}^{2}$, the growth rate of IMC was $0.212 \mu \mathrm{m} / \mathrm{min}$. The TLPB bonding time with applying current was reduced by keeping the growth rate of IMC nearly constant. This phenomena occurred due to the selective $\mathrm{Cu}$ dissolution by electromigration. However, the applied current might have a negative effect on the chip reliability and this issue needs to be solved in future study ${ }^{14)}$.

\subsection{Application of induction heating during TLPB}

Yin et $a l{ }^{27)}$ used TLPB for $\mathrm{Cu} / \mathrm{Sn} / \mathrm{Cu}$ structure with induction heating. Induction heating is a heating process using an electromagnetic field. TLPB using induction heating increases the bonding temperature over time. The bonding temperature gradually increased to $350{ }^{\circ} \mathrm{C}$ for 55 seconds and reached $535{ }^{\circ} \mathrm{C}$ for 220 seconds. Fig. 5 shows the scallop type $\mathrm{Cu}_{6} \mathrm{Sn}_{5}$ transforming to dendritic morphology. This is due to the undercooling effect with the bonding temperature increasing gradually during TLPB. Furthermore, a planar type $\mathrm{Cu}_{3} \mathrm{Sn}$ transforms to columnar type. Total bonding time of 270 seconds was consumed using a Sn interlayer with a thickness of $10 \mu \mathrm{m}^{21)}$. The conventional TLPB also completed the process in less than a few minutes at high temperature approximately $350{ }^{\circ} \mathrm{C}$. Therefore, TLPB
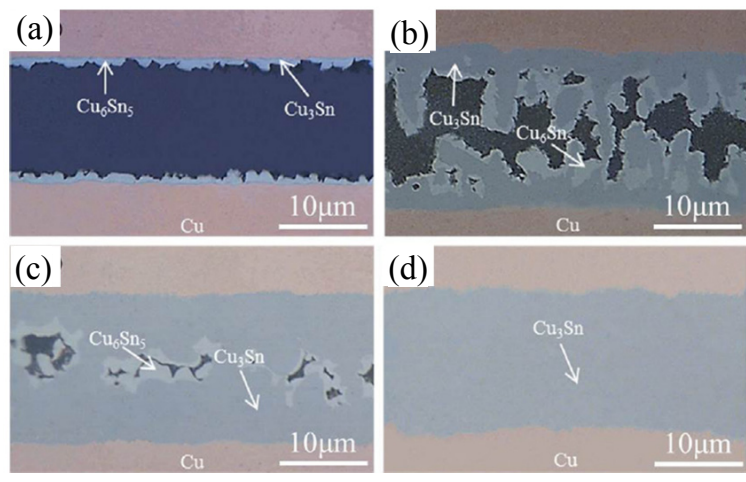

Fig. 5 Cross-sectional morphology of the deep-etched $\mathrm{Cu} / \mathrm{Sn} / \mathrm{Cu}$ sandwich structure for various durations: (a) $20 \mathrm{~s}$, (b) $55 \mathrm{~s}$, (c) $220 \mathrm{~s}$, and (d) $270 \mathrm{~s}^{27}$ ) using induction heating did not show a great effect on reducing the bonding time. Unlike conventional TLPB, induction heating is applied to the component indirectly during TLPB, therefore reducing the heat attack to the component. For the reason, it is necessary to study this process further and to investigate whether the magnetic field induced by induction heating affects the reliability of the device.

\subsection{Application of ultrasonic wave during TLPB}

Ultrasonic-assisted TLPB is a recent process that has been actively studied. Ultrasonic wave is applied to TLPB to produce microbubble in the joint ${ }^{28,29)}$. Forming microbubbles in the liquid interlayer, the temperature and pressure reached locally $5000 \mathrm{~K}$ and $0.1 \mathrm{GPa}$, respectively, due to the of bubble implosion ${ }^{29)}$. In such an environment, micropits are generated at metallization, and strong metallization dissolution occurs. In addition, the repetition of the formation, growth and implosion of the microbubble allows the liquid interlayer to be supersaturated with dissolved metallization element. The supersaturation state of the liquid disappears with removing ultrasound, therefore producing IMC nuclei and growing simultaneously in the middle of the liquid interlayer. Severe dissolution of metallization and supersaturation of the liquid with the dissolved metallization reduces significantly the TLPB time.

Li et al. $^{29)}$ applied the conventional TLPB to Ni/Sn/Ni structure with a Sn interlayer with a thickness of $20 \mu \mathrm{m}$ at $250{ }^{\circ} \mathrm{C}$ and the TLPB was completed in 120 minutes. Fig. 6 shows the TLPB joint with no defects and the IMC having a columnar structure in conventional TLPB. In contrast, when the same structure was subjected to ultrasonic-assisted TLPB at $250{ }^{\circ} \mathrm{C}$, the TLPB was completed in 8 seconds and no defects were observed. Fig. 7 indicates that Ni-supersaturated liquid $\mathrm{Sn}$ was cooled in air and IMC was formed and grew at the metallization interface as well as in the middle of liquid $\mathrm{Sn}$ due to constitutional cooling, which led to equiaxed grains. Despite the short bonding time of the ultrasonic-assisted TLPB, the local-high pressure and temperature environments due to ultrasound cause the con-
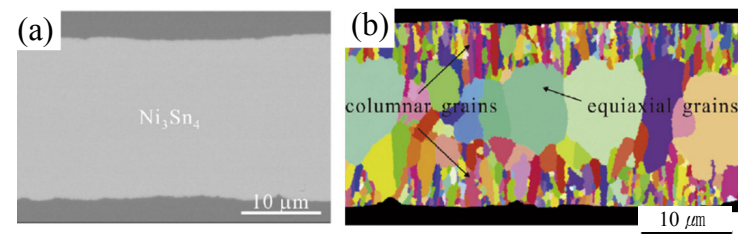

Fig. 6 Cross-sectional images of the joint formed by the reflow TLPB process for $120 \mathrm{~min}$ at $250{ }^{\circ} \mathrm{C}$ : (a) SEM and (b) EBSD showing Ni3Sn4 grain mapping image ${ }^{29)}$ 

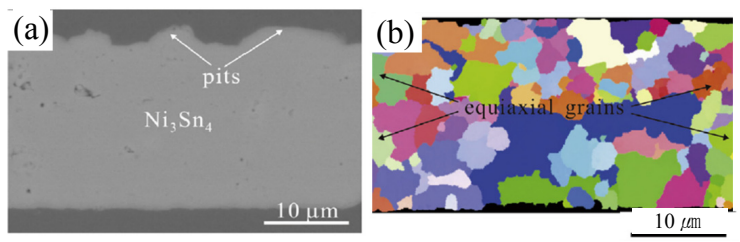

Fig. 7 Cross-sectional images of the joint formed by the ultrasound-induced TLPB process for $8 \mathrm{~s}$ at 250 ${ }^{\circ} \mathrm{C}$ : (a) SEM and (b) EBSD showing $\mathrm{Ni}_{3} \mathrm{Sn}_{4}$ grain mapping image ${ }^{29)}$

cern to degrade device reliability. Therefore, it needs a further improvement for the commercial use.

\section{Interlayer design to reduce TLPB time}

\subsection{Alloy design of paste}

Many studies on the TLPB interlayer have used the powder paste consisting of $\mathrm{Ag}, \mathrm{Sn}, \mathrm{Cu}, \mathrm{Ni}$, and other minor elements. Bao et $a l^{30)}$ studied the TLPB of $\mathrm{Cu} / \mathrm{Sn}-\mathrm{Ag} / \mathrm{Cu}$ structure using the $\mathrm{Sn}-\mathrm{Ag}$ paste that has excellent thermal and electrical properties as an interlayer. Interlayers were fabricated with the various Ag content and Sn particle size. The Ag contents were in the range of $60-80 \mathrm{wt} \%$, and the Sn particles had a diameter of 1-20 $\mu \mathrm{m}$. The joining conditions were nearly constant for the Ag-based interlayers at $300{ }^{\circ} \mathrm{C}$ for $60 \mathrm{~min}$. For the $\mathrm{Ag}$ content of $70 \mathrm{wt} \%$, the TLPB joint produced the lowest pores and the highest shear strength. This is consistent with the previous study ${ }^{31)}$. For the Ag content below $70 \mathrm{wt} \%$, the $\mathrm{Sn}$ powder was remained without reaction, which caused volume shrinkage and voids during air cooling after bonding. $\mathrm{Ag}_{3} \mathrm{Sn}$ could not be merged by insufficient Sn when the Ag contents exceeded $70 \mathrm{wt} \%$. Fig. 8 shows void formation when $\mathrm{Ag}_{3} \mathrm{Sn}$ does not merge or coalesce with each other. Since $\mathrm{Ag}_{3} \mathrm{Sn}$ is a skeleton type, the void formation was inevitable in the process. The Sn particles of a large size had excellent joint characteristics considering oxidation. The Sn-Ag paste played the role of reducing the bonding time compared to the $\mathrm{Sn}$ foil used in conventional TLPB. This was because the interface area between the $\mathrm{Ag}$ and $\mathrm{Sn}$ of the powder increased and the diffusion distance decreased as compared to the foil interlayer. However, the void using the interlayer paste is a disadvantage as compared with the conventional TLPB using a Sn foil.

\subsection{Design of Sn-coated particle}

Yu et al. ${ }^{32)}$ used a preform consisting of micro-sized Sn-coated Ag particles for the interlayer to reduce the TLPB time. The Ag/interlayer/Ag structure was used for the interlayer that had the thickness of $150 \mu \mathrm{m}$. The bonding temperature and time were $250{ }^{\circ} \mathrm{C}$ and $10 \mathrm{~min}$, respectively. Fig. 9 shows the joints produced with $\mathrm{Ag}_{3} \mathrm{Sn}$ and the joining was completed in $10 \mathrm{~min}$. The distance for Ag metallization to diffuse was extremely reduced during the TLPB as compared to the conventional TLPB. For the conventional TLPB having a same interlayer thickness of $150 \mu \mathrm{m}$, the distance for the metallization to diffuse was $75 \mu \mathrm{m}$ to produce IMC completely in the joint. However, Sn-coated Ag particles reduced the diffusion distance to coated Sn layer thickness of $0.4 \mu \mathrm{m}$. Since the Sn-coated Ag particles has the large total surface area, the area diffused during the same period of TLPB process is larger than that during the conventional TLPB. Therefore, the bonding process was completed in a few minutes despite the thick interlayer. The use of the thick interlayer was also able
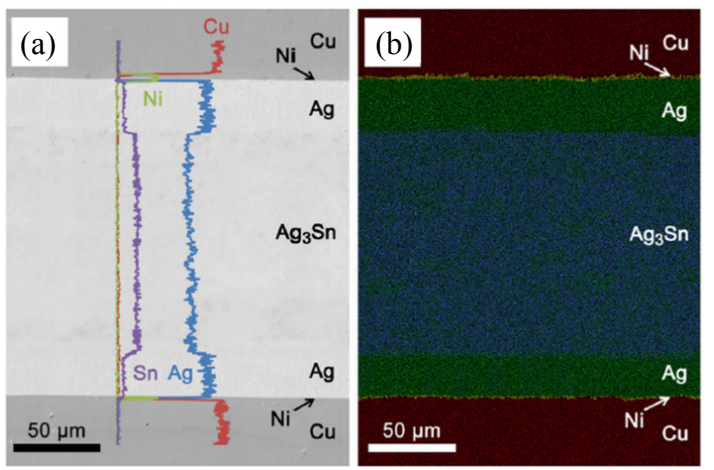

Fig. 9 Cross-sectional SEM of the reflowed bondline: (a) high-magnification image of the bondline and the EDS line scan profiles acquired across the bondline; (b) elemental mapping near the bondline in $(\mathrm{a})^{32)}$
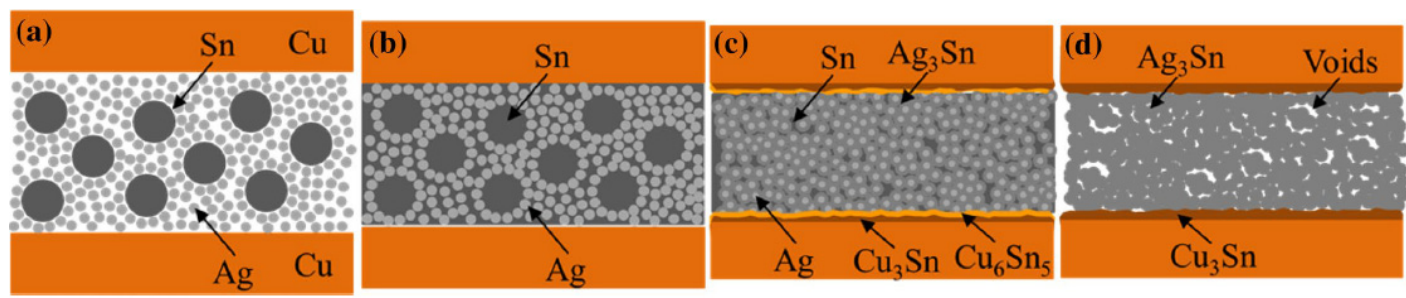

Fig. 8 Illustration of void formation in $\mathrm{Cu} / \mathrm{Sn}-\mathrm{Ag} / \mathrm{Cu}$ joint: (a) before bonding; (b) melting of Sn particles; (c, d) reaction of liquid $\mathrm{Sn}$ and $\mathrm{Ag}$ particles/Cu substrates ${ }^{30}$ 
to reduce the residual stress resulting from differences in CTE of components.

A multilayer particle was also applied in $\mathrm{TLPB}^{33)}$. The preform was prepared by coating the $\mathrm{Cu}$ particles with $\mathrm{Ag}$ and Sn. This approach solved the high cost of Ag in Sn-coated Ag particles. In addition, the low diffusion rate of $\mathrm{Cu}$ was also improved with a thin coating of $\mathrm{Ag}$. The joining time was greatly reduced by decreasing the diffusion distance and increasing the surface area. However, in order to commercialize Sn-coated particles, it is necessary to simplify the fabrication of the preform.

\subsection{Design of particle-introduced interlayer}

Introducing particles into the interlayer was studied on the void formation in TLPB. Xiong et al. ${ }^{34)}$ applied TLPB to $\mathrm{Cu} / \mathrm{Sn} 58 \mathrm{Bi} / \mathrm{Cu}$ structure, in which the $\mathrm{CuZnAl}$ particles were introduced into the Sn58Bi interlayer. Fig. 10 shows that $\mathrm{CuZnAl}$ particles suppressed the void formation during TLPB compared to the conventional $\mathrm{Sn} 58 \mathrm{Bi}$ interlayer. The void formation was due to the unbalanced diffusion rate between $\mathrm{Cu}$ and $\mathrm{Sn}$. The $\mathrm{Bi}$ particles suppressed the diffusion of dissolved $\mathrm{Cu}$ elements and the volume shrinkage produced in transformation from $\mathrm{Cu}_{3} \mathrm{Sn}$ to $\mathrm{Cu}_{6} \mathrm{Sn}_{5}$. The addition of $\mathrm{CuZnAl}$ particles increased the activation energy for diffusion and caused the adsorption of $\mathrm{CuZnAl}$ to $\mathrm{Cu}_{6} \mathrm{Sn}_{5}$, thereby suppressing diffusion and segregation of $\mathrm{Bi}$. The $\mathrm{CuZnAl}$ particles introduced in the interlayer reduced the unbalanced diffusion between $\mathrm{Cu}$ and $\mathrm{Sn}$, which led to suppressing IMC growth. Therefore, the bonding time using the $\mathrm{CuZnAl}$ particle-introduced interlayer

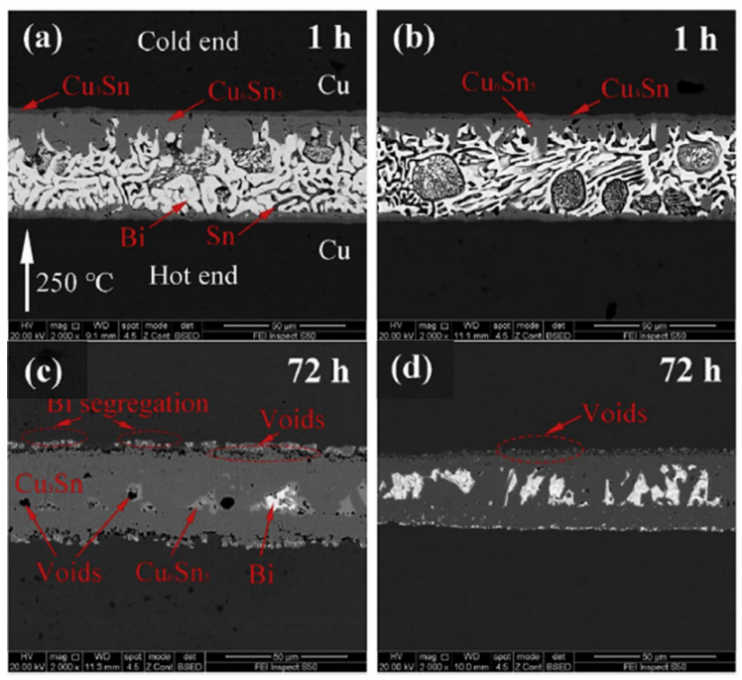

Fig. 10 SEM micrographs of interfaces using various particle-introduced interlayers: (a, c) $\mathrm{Cu} / \mathrm{Sn} 58 \mathrm{Bi} /$ $\mathrm{Cu} ; \quad(b, d) \quad \mathrm{Cu} / \mathrm{Sn} 58 \mathrm{Bi}-0.5 \mathrm{CuZnAl} / \mathrm{Cu}$. The bonding process was conducted at $250{ }^{\circ} \mathrm{C}$ for (a, b) $1 \mathrm{~h}$ and (c, d) $72 \mathrm{~h}^{34)}$ was longer than that of the conventional TLPB. This new process needs to be performed in combination with a process that increases the growth rate of IMC.

\subsection{Design of metallization-added interlayer}

Sohn et al. ${ }^{35)}$ used pure-Sn, Sn-3Cu, and $\mathrm{Sn}-10 \mathrm{Cu}$ alloys for the TLPB interlayer in $\mathrm{Cu} /$ interlayer $/ \mathrm{Cu}$ structure. If $\mathrm{Cu}$ was added more than $0.7 \mathrm{wt} \%$ in $\mathrm{Sn}-\mathrm{Cu}$ binary system, primary $\mathrm{Cu}_{6} \mathrm{Sn}_{5}$ was formed. In the range of 2-10 wt $\%$ of $\mathrm{Cu}$, primary $\mathrm{Cu}_{6} \mathrm{Sn}_{5}$ was not dissolved during TLPB at $250{ }^{\circ} \mathrm{C}$. Therefore, the primary IMC in the interlayer was introduced in advance before the TLPB. Since the IMC was pre-existed in the interlayer, the diffusion distance and bonding time were reduced significantly. Fig. 11 shows the primary IMC that is not dissolved in the TLPB and coalesced with new IMC produced during the TLPB. Analyzing the kinetics of IMC growth during TLPB, addition of $\mathrm{Cu}$ did not decrease IMC growth kinetics. This TLPB process has the advantage that the interlayer fabrication is simpler than the Sn-coated particles. This process using a metallization-added interlayer reduced the TLPB time as compared to the conventional TLPB. However, an interlayer design for the commercialized use is required to reduce the bonding time to a few minutes. For this reason, it is necessary to further increase the $\mathrm{Cu}$ composition and control the microstructure of the interlayer by optimizing the size and distribution of the primary $\mathrm{Cu}_{6} \mathrm{Sn}_{5}$. It is also necessary to introduce the metallization elements other than $\mathrm{Cu}$ into the interlayer to control the void formation.

\section{Conclusions}

WBG power semiconductors increase the demand rapidly in recent years and various fields. The WBG power semiconductors are necessarily required to operate in higher temperature than the conventional Si semiconductors.

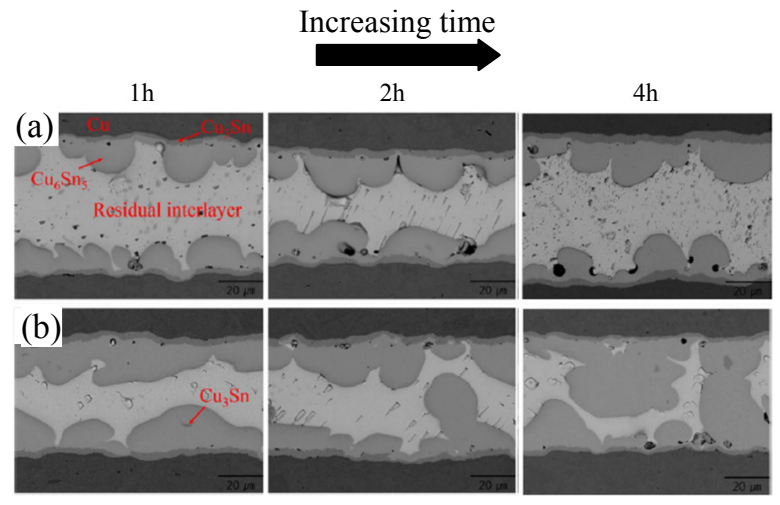

Fig. 11 Microstructure of TLPB for 1, 2, and $4 \mathrm{~h}$ using various interlayers: (a) $\mathrm{Sn}$; (b) $\mathrm{Sn}-10 \mathrm{Cu}^{35)}$ 
In the case of the military applications, the WBG semiconductors are needed to operate in extreme environment and to establish a robust interconnect. The TLPB is one of the method to produce the WBG power semiconductor. The TLPB produces an IMC having a melting point higher than the process temperature. In order to produce the entire IMC in the joint, it is necessary for metallization with the high melting point to diffuse. Therefore, the TLPB has a disadvantage of long process time. For the commercialized use of TLPB, the IMC formation needs to be completed less than a few minutes. For that purpose, many researchers are developing the new process and design of an interlayer. New TLPB process maintained the constant dissolution rate due to the selective metallization dissolution, which significantly reduced the bonding time. The interlayer design significantly reduced the diffusion distance of metallization for IMC formation and growth, therefore reducing the bonding time. Methods for suppressing voids during the TLPB were also investigated. In spite of various advantages, process development poses problems in terms of compatibility with the packaging industry and lowering the reliability of devices. Interlayer design, which is well matched to the packaging industry, also requires simplification of the interlayer fabrication and more reduced time for joining. Therefore, it is necessary to combine the process development and interlayer design of TLPB, followed by optimizing the TLPB process.

\section{Acknowledgements}

This research was supported by a 2-year research grant of Pusan National University.

ORCID: Sunghyun Sohn: http://orcid.org/0000-0001-8722-3407

ORCID: Namhyun Kang: http://orcid.org/0000-0002-9460-5128

\section{References}

1. B. K. Bose, Evaluation of Modern Power Semiconductor Devices and Future Trends of Converters, IEEE Trans. Ind. Appl. 28(2) (1992) 403-413. https://doi.org/10.1109/28.126749

2. C. Buttay, D. Planson, B. Allard, D. Bergogne, P. Bevilacqua, C. Joubert, M. Lazar, C. Martin, H. Morel, D. Tournier and C. Raynaud, State of the art of high temperature power electronics, Mater. Sci. Eng. B: Solid-State Mater. Adv. Technol. 176(4) (2011) 283-288. https://doi.org/10.1016/j.mseb.2010.10.003

3. J. Lee, D. Jung, S. Oh and J. Jung, High Technology and Latest Trends of WBG Power Semiconductors, J. Microelectron. Packag. Soc. 25(4) (2018) 17-23. https://doi.org/10.6117/kmeps.2018.25.4.017
4. T. Ericsen, Future navy application of wide bandgap power semiconductor devices, Proc. IEEE. 90(6) (2002) 10771082. https://doi.org/10.1109/JPROC.2002.1021572

5. S. W. Yoon, M. D. Glover and K. Shiozaki, Nickel-tin transient liquid phase bonding toward high-temperature operational power electronics in electrified vehicles, IEEE Trans. Power Electron. 28(5) (2013) 2448-2456. https://doi.org/10.1109/TPEL.2012.2212211

6. J. W. Xian, S. A. Belyakov and C. M. Gourlay, Controlling Bulk Cu6Sn5 Nucleation in $\mathrm{Sn} 0.7 \mathrm{Cu} / \mathrm{Cu}$ Joints with Al Micro-alloying, J. Electron. Mater. 45(1) (2016) 69-78. https://doi.org/10.1007/s11664-015-4092-y

7. H. Lee, V. Smet and R. Tummala, A Review of SiC Power Module Packaging Technologies: Challenges, Advances, and Emerging Issues, IEEE J. Emerg. Sel. Top. Power Electron. 8(1) (2020) 239-255. https://doi.org/10.1109/JESTPE.2019.2951801

8. H. A. Mustain, W. D. Brown and S. S. Ang, Transient liquid phase die attach for high-temperature silicon carbide power devices, IEEE Trans. Components Packag. Technol. 33(3) (2010) 563-570. https://doi.org/10.1109/TCAPT.2010.2046901.

9. G. Zeng, S. McDonald and K. Nogita, Development of high-temperature solders: Review, Microelectron. Reliab. 52(7) (2012) 1306-1322. https://doi.org/10.1016/j.microrel.2012.02.018

10. L. S. Pei, B. Pan, H. Zhang, W. Ng, B. Wu, K. S. Siow, S. Sabne and M. Tsuriya, High-Temperature Pb-Free Die Attach Material Project Phase 1 : Survey Result, International Conference on Electronics Packaging (ICEP), Yamagata, Japan (2017) 51-56.

11. H. Zhang, J. Minter and N. C. Lee, A Brief Review on High-Temperature, Pb-Free Die-Attach Materials, $J$. Electron. Mater. 48(1) (2019) 201-210. https://doi.org/10.1007/s11664-018-6707-6

12. W. S. Hong, G. Goo and U. H. Hwang, Verification Guideline of Pb-free Solder Joint Reliability for Military Electronics, J. Korean. Weld. Soc. 30(3) (2012) 242-248. https://doi.org/10.5781/KWJS.2012.30.3.242

13. M. Ohadi and J. Qi, Thermal Management of HarshEnvironment Electronics, Twentieth Anmual IEEE Semiconductor Thermal Measurement and Management Symposium, San Jose, Ca, USA (2004) 231-240.

14. B. Hu, F. Yang, Y. Peng, H. Ji, S. Yang, M. Yang and M. $\mathrm{Li}$, Rapid formation of $\mathrm{Cu}-\mathrm{Cu}$ joints with high shear strength using multiple-flocculated Ag nanoparticle paste, J. Mater. Sci. Mater. Electron. 30(8) (2019) 8071-8079. https://doi.org/10.1007/s10854-019-01129-y

15. M. H. Roh, H. Nishikawa and J. P. Jung, A Review of Ag Paste Bonding for Automotive Power Device Packaging, J. Microelectron. Packag. Soc. 22(4) (2015) 15-23. https://doi.org/10.6117/kmeps.2015.22.4.015

16. M.-H. Roh, H. Nishikawa, J. P. Jung and W. Kim, Trasient 
Liquid Phase bonding for Power Semiconductor, J. Microelectron. Packag. Soc. 24(1) (2017) 27-34. https://doi.org/10.6117/kmeps.2017.24.1.027

17. W. Zhang, J. Chen, Z. Deng, Z. Liu, Q. Huang, W. Guo and J. Huang, The pressureless sintering of micron silver paste for electrical connections, J. Alloys Compd., 795(4) (2019) 163-167. https://doi.org/10.1016/j.jallcom.2019.04.270

18. K. S. Siow and S. T. Chua, Thermal Ageing Studies of Sintered Micron-Silver (Ag) Joint as a Lead-Free Bonding Material, Met. Mater. Int., (2019). https://doi.org/10.1007/s12540-019-00394-0

19. J. W. Yoon, J. H. Back and S. B. Jung, Effect of surface finish metallization on mechanical strength of Ag sintered joint, Microelectron. Eng. 198(7) (2018) 15-21. https://doi.org/10.1016/j.mee.2018.06.009

20. G. O. Cook and C. D. Sorensen, Overview of transient liquid phase and partial transient liquid phase bonding, J. Mater. Sci. 46(16) (2011) 5305-5323. https://doi.org/10.1007/s10853-011-5561-1

21. M. S. Park, S. L. Gibbons and R. Arróyave, Prediction of processing maps for transient liquid phase diffusion bonding of $\mathrm{Cu} / \mathrm{Sn} / \mathrm{Cu}$ joints in microelectronics packaging, Microelectron. Reliab., 54(6) (2014) 1401-1411. https://doi.org/10.1016/j.microrel.2014.02.023

22. O. Mokhtari, A review: Formation of voids in solder joint during the transient liquid phase bonding process - Causes and solutions, Microelectron. Reliab. 98(10) (2018) 95-105. https://doi.org/10.1016/j.microrel.2019.04.024

23. N. Zhao, Y. Zhong, M. L. Huang, H. T. Ma and W. Dong, Growth kinetics of $\mathrm{Cu}_{6} \mathrm{Sn}_{5}$ intermetallic compound at liquid-solid interfaces in $\mathrm{Cu} / \mathrm{Sn} / \mathrm{Cu}$ interconnects under temperature gradient, Sci. Rep., 5(1) (2015) 1-12. https://doi.org/10.1038/srep13491

24. S. Baek, Y. Park, C. Oh, E. Chun and N. Kang, Modeling and experimental verification of intermetallic compounds grown by electromigration and thermomigration for Sn-0.7Cu solders, J. Elctron. Mater., 48(1) (2019) 142-151. https://doi.org/10.1007/s11664-018-6786-4

25. M. Heo, N. Kang, S. Park, J. Kim and W. Hong, Kinetics of Intermetallic Compounds Growth Induced by Electromigration of Sn-0.7Cu Solder, Korean J. Met. Mater. 54(12) (2016) 908-915. https://doi.org/10.3365/KJMM.2016.54.12.908

26. J. Feng, C. Hang, Y. Tian, B. Liu and C. Wang, Growth kinetics of $\mathrm{Cu}_{6} \mathrm{Sn}_{5}$ intermetallic compound in $\mathrm{Cu}$-liquid Sn interfacial reaction enhanced by electric current, Sci. Rep. 8(1) (2018) 1-10. https://doi.org/10.1038/s41598-018-20100-1
27. Z. Yin, F. Sun and M. Guo, The fast formation of $\mathrm{Cu}-$ $\mathrm{Sn}$ intermetallic compound in $\mathrm{Cu} / \mathrm{Sn} / \mathrm{Cu}$ system by induction heating process, Mater. Lett. 215 (2018) 207-2 10 .

https://doi.org/10.1016/j.matlet.2017.12.102

28. H. Shao, A. Wu, Y. Bao, Y. Zhao, L. Liu and G. Zou, Rapid $\mathrm{Ag} / \mathrm{Sn} / \mathrm{Ag}$ transient liquid phase bonding for high-temperature power devices packaging by the assistance of ultrasound, Ultrason. Sonochem. 37 (2017) 561-570. https://doi.org/10.1016/j.ultsonch.2017.02.016

29. Z. L. Li, H. J. Dong, X. G. Song, H. Y. Zhao, J. C. Feng, J. H. Liu, H. Tian and S. J. Wang, Rapid formation of $\mathrm{Ni}_{3} \mathrm{Sn}_{4}$ joints for die attachment of SiC-based high temperature power devices using ultrasound-induced transient liquid phase bonding process, Ultrason. Sonochem., 36 (2017) 111-120.

https://doi.org/10.1016/j.ultsonch.2016.12.026

30. Y. Bao, A. Wu, H. Shao, Y. Zhao and G. Zou, Effect of powders on microstructures and mechanical properties for $\mathrm{Sn}-\mathrm{Ag}$ transient liquid phase bonding in air, J. Mater. Sci. Mater. Electron. 29(12) (2018) 10246-10257. https://doi.org/10.1007/s10854-018-9076-2

31. A. Sharif, C. L. Gan and Z. Chen, Transient liquid phase Ag-based solder technology for high-temperature packaging applications, J. Alloys Compd. 587 (2014) 365-368. https://doi.org/10.1016/j.jallcom.2013.10.204

32. F. Yu, H. Liu, C. Hang, H. Chen and M. Li, Rapid Formation of Full Intermetallic Bondlines for Die Attachment in High-Temperature Power Devices Based on Micro-sized Sn-Coated Ag Particles, Jom, 71(9) (2019) 3049-3056. https://doi.org/10.1007/s11837-019-03544-2

33. F. Yu, H. Chen, C. Hang and M. Li, Fabrication of high-temperature-resistant bondline based on multilayer core-shell hybrid microspheres for power devices, J. Mater. Sci. Mater. Electron. 30(4) (2019) 35953603. https://doi.org/10.1007/s10854-018-00637-7

34. M. Xiong, L. Zhang, L. Sun, P. He and W. Long, Effect of $\mathrm{CuZnAl}$ particles addition on microstructure of $\mathrm{Cu} / \mathrm{Sn} 58 \mathrm{Bi} / \mathrm{Cu}$ TLP bonding solder joints, Vacuum, 167(3) (2019) 301-306. https://doi.org/10.1016/j.vacuum.2019.06.024

35. S. Sohn, B. Moon, J. Lee, N. Kang and Y. Moon, Interlayer Material Design Reducing Transient Liquid Phase Bonding Time, Electron. Mater. Lett. 16(2) (2020) 106114.

https://doi.org/10.1007/s13391-019-00191-2 